\title{
CONF- $960401--19$
}

NANOINDENTATION OF SOFT FILMS ON HARD SUBSTRATES: THE IMPORTANCE OF PILE-UP

\author{
T.Y. TSUI*, W.C. OLIVER**, and G.M. PHARR* \\ * Department of Materials Science, Rice University, 6100 Main St., Houston, TX 77005 \\ ** Nanoinstruments Inc., 1001 Larson Drive, Oak Ridge, TN 37830
}

\section{ABSTRACT}

Nanoindentation is a common technique for measuring the mechanical properties of thin films. Here, we address the potential measurement errors caused by pile-up when soft films deposited on hard substrates are tested by nanoindentation methods. Pile-up is exacerbated in soft film / hard substrate systems because of the constraint the substrate exerts on plastic deformation of the film. To experimentally examine pile-up effects, aluminum films with thicknesses of 240 and $1700 \mathrm{~nm}$ were deposited on hard glass substrates and tested by standard nanoindentation techniques. The aluminum/glass system is interesting because the film and substrate have similar elastic moduli; thus, any unusual behavior in the nanoindentation results may be attributed to differences in the plastic flow characteristics alone. A detailed scanning electron microscopy examination of nanoindentation hardness impressions in the film revealed that common methods for analyzing nanoindentation data underestimate the true contact areas by as much as $80 \%$, which results in overestimations of the hardness and modulus by as much as $80 \%$ and $35 \%$, respectively. The sources of these errors and their influence on the measurement of hardness and elastic modulus are discussed, and a simple model for the composite hardness of the film/substrate system is developed. The model could prove useful in measuring the hardness and elastic modulus of soft-film / hard substrate systems when it is not possible to make indentations shallow enough to avoid the substrate influences.

\section{INTRODUCTION}

Nanoindentation is a widely used technique for measuring mechanical properties on the micron and sub-micron scale [1,2]. The technique has proven particularly useful for measuring the properties of thin films, since measurements can often be made without having to remove the film from its substrate [2]. However, when the film is very thin, e.g., less than a micron, accurate measurements are sometimes difficult to obtain because the substrate can influence the indentation load-displacement behavior. As a result, numerous experimental and theoretical investigations have addressed the issue of substrate effects and what can be done in the analysis of nanoindentation data to obtain substrate independent measurements of mechanical properties [3-11]. Most work to date has focused on the measurement of hardness, $\mathrm{H}$, and elastic modulus, E.

Many thin film systems are comprised of very soft films on very hard substrates. This is particularly common, for instance, in the semiconductor industry, where films of aluminum, gold and copper are often deposited on silicon $(\mathrm{H}=12 \mathrm{GPa})$, germanium $(\mathrm{H}=10 \mathrm{GPa})$, glass $(\mathrm{H}=5-8 \mathrm{GPa})$ and ceramic substrates $(\mathrm{H}=10-40 \mathrm{GPa})$. The hardness of these films is usually in the range 0.1-1 GPa, making them at least an order of magnitude softer than the materials on which they are deposited. One important consequence is that when a hardness impression is made, there is a tendency for material to pile-up around the hardness impression to a much greater degree than it would in a bulk material. This is due to the severe constraint imposed on plastic deformation in the film by the relatively undeformable substrate. Since current techniques for analyzing nanoindentation data do not make provisions for the extra contact area produced by the pile-up, the enhancement of pile-up in soft films on hard substrates has important consequences for the measurement of mechanical properties by nanoindentation methods. This may be seen, for example, by considering the equations used to extract $\mathrm{H}$ and $\mathrm{E}$ from nanoindentation load-displacement data. They are [1]:

"The submitted manuscript has been authored by a contracter of the U.S. Goverrment under contract No. DE-AC05-96OR22464. Accordingly, the U.S. Government retains a nonexclusive, royally-tree license to publish or reproduce the published form of this to publish of feproduce the published form of this
contribution, or allow others to do so, for U.S. Government purposes." 
and

$$
H=\frac{P}{A}
$$

$$
E_{\text {eff }}=\frac{E}{1-v^{2}}=\frac{\sqrt{\pi}}{2} \frac{S}{\sqrt{A}},
$$

where $\mathrm{P}$ is the indentation load, $\mathrm{A}$ is the projected area of the contact, $\mathrm{E}_{\text {eff }}$ is the effective elastic modulus defined in terms of Young's modulus $E$ and Poisson's ratio $v$, and $S$ is the experimentally measured contact stiffness. The contact area in nanoindentation measurements is indirectly deduced from an analysis of unloading data which does not account for pile-up. Thus, in materials which are prone to pile-up, an error in the contact area introduces an error of similar magnitude into the hardness and and an error which scales as $A^{1 / 2}$ in the elastic modulus. As documented elsewhere $[12,13]$, similar effects explain the apparent dependence of the nanoindentation hardness and elastic modulus on residual stress.

In order to gain a better understanding of how significant pile-up errors may be for soft films on hard substrates, we recently undertook an experimental investigation of the pile-up behavior of a model system. Here, we report some important observations of that study and discuss their implications for mechanical property measurement by nanoindentation methods.

\section{EXPERIMENTAL PROCEDURE}

The model system used in the investigation was high purity aluminum deposited on glass. In addition to a large difference in hardness (the hardness of the film is about $0.5 \mathrm{GPa}$ while that for the substrate is $7.0 \mathrm{GPa}$ ), an equally important consideration in choosing this system was the similarity of the elastic moduli of the two components. The modulus of bulk aluminum is 70 $\mathrm{GPa}$, while that for the glass used in the study was $57 \mathrm{GPa}$. The fact that the moduli are so similar minimizes the role that a film/substrate modulus difference would play in determining the indentation behavior, thus simplifying the interpretation of results.

The films were sputter-deposited to two different thicknesses, $t_{f}=240 \mathrm{~nm}$ and $1700 \mathrm{~nm}$, and indented to various penetration depths, $h_{t}$, in the range 0.1-10 $t_{f}$ with a sharp Berkovich indenter. The load-displacement data obtained at each depth were analyzed using the method of Oliver and Pharr [1] to determine the apparent contact area, hardness, and elastic modulus. Such measurements do not account for substrate influences. The quantities measured in this way will be referred to throughout this paper as $A_{\text {nano }}, H_{\text {nano, }}$ and $E_{\text {nano. }}$. Subsequently, the larger indentations were imaged in a high resolution scanning electron microscope (SEM) to determine their actual contact areas, $A_{\text {actual }}$. Care was taken in these measurements to include the pile-up in the contact area determination. This was accomplished by tracing a digital image of each indentation along the contact edge and computing the area enclosed inside the figure. The $A_{\text {actual }}$ were then used in conjunction with Eqns. 1 and 2 to provide a second measurement of the hardness and modulus, $\mathrm{H}_{\text {actual }}$ and $\mathrm{E}_{\text {actual }}$, based on the actual contact areas. Note that the hardness measured in this way is, by definition, the true hardness. Thus, any deviations of $\mathrm{H}_{\text {nano }}$ from $\mathrm{H}_{\text {actual }}$ must be attributed to inaccuracies in the procedure by which contact areas are deduced from the experimental load-displacement data.

\section{RESULTS AND DISCUSSION}

Figure 1 summarizes the results of the hardness and modulus measurements for the 1700 $\mathrm{nm}$ film. The thickness of this film makes it convenient for measurements at penetration depths less than film thickness $\left(h_{t} \leq t_{f}\right)$. Later on, data for the $240 \mathrm{~nm}$ film will be presented to illustrate the behavior for $h_{t} \geq t_{f}$.

The filled symbols in Figs. $1 \mathrm{a}$ and $\mathrm{lb}$ show the dependencies of $\mathrm{H}_{\text {nano }}$ and $\mathrm{E}_{\text {nano }}$ on the maximum penetration depth normalized with respect to the film thickness, i.e., $h_{t / f} t_{f}$ The behavior of the composite hardness of the film/substrate system based on these data seems 

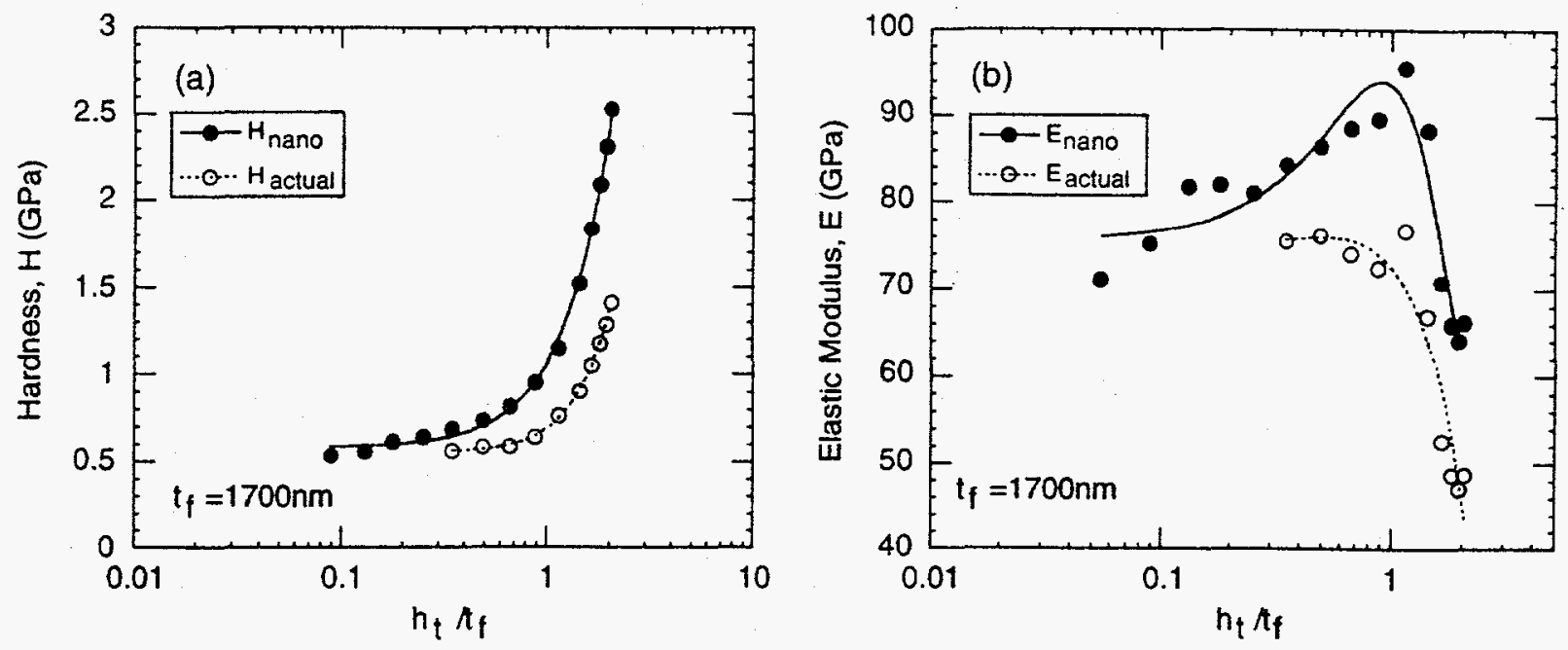

Fig. 1. Hardness and elastic modulus of $1700 \mathrm{~nm}$ aluminum films on glass substrates.

perfectly reasonable. At small depths, the hardness tends toward a limiting value of about 0.5 $\mathrm{GPa}$, presumably the hardness of the film, but at large depths, the hardness increases markedly, consistent with a substrate hardness of $7.0 \mathrm{GPa}$. Note that most of the increase occurs at penetration depths close to the film thickness. The behavior of the elastic modulus, on the other hand, is quite different. At small depths, $E_{\text {nano }}$ is close to the expected film modulus of $70 \mathrm{GPa}$, but as the depth increases, the modulus shows an unexpected increase into the $90-100 \mathrm{GPa}$ range. The modulus then peaks at a penetration depth very close to the film thickness, followed by an abrupt decrease. The non-constancy of the modulus and increases above $70 \mathrm{GPa}$ are especially perplexing given that modulus of the substrate, $57 \mathrm{GPa}$, is smaller that of the film.

The reason for the increase in the elastic modulus above that of the film and substrate is directly related to the pile-up behavior. Fig. 2 presents SEM images of indentations made at three different normalized depths: $h_{\max } / t_{f}=0.18,1.43$, and 9.96. The first two indentations were made in the $1700 \mathrm{~nm}$ film, and the third in the $240 \mathrm{~nm}$ film. What is apparent from an examination of these micrographs is that the pile-up behavior depends on the depth of the indentation relative to the film thickness and that the amount of pile-up can be quite large under certain circumstances. At small depths (Fig. 2a), there is very little pile-up, consistent with the behavior of well-annealed, bulk aluminium. However, at depths close to the film thickness (Fig. $2 \mathrm{~b}$ ), the amount of pile-up is substantial, giving the indentation a circular appearance even though it was made with a triangular pyramid. For depths much greater than the film thickness (Fig. 2c), the amount of the pile-up is not as large because a greater portion of the deformed volume is in the hard glass substrate. Thus, it is apparent that the constraint that the hard
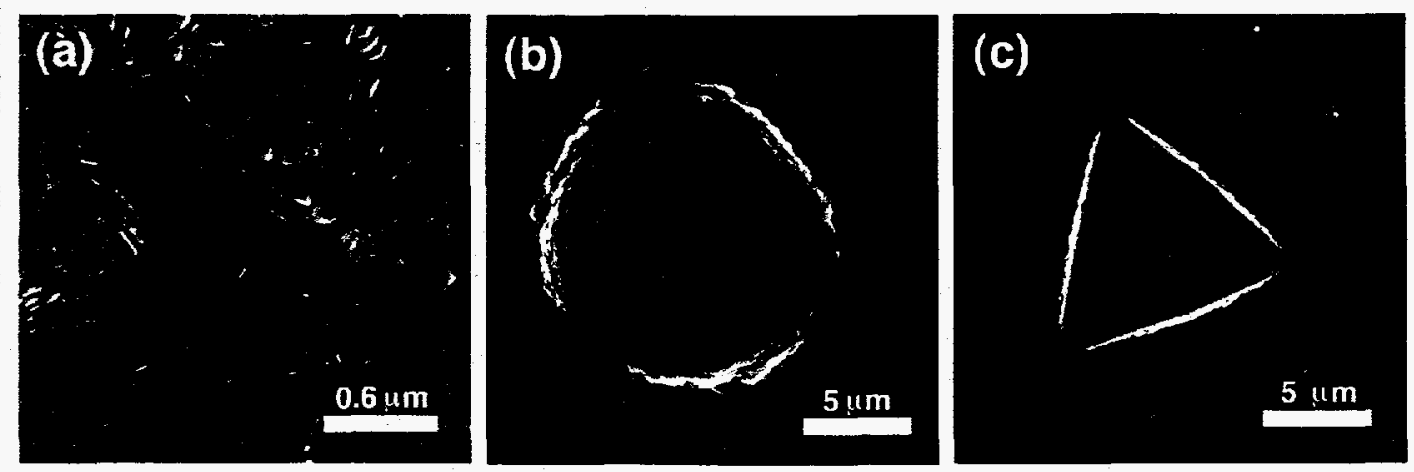

Fig. 2. SEM images of indentations: (a) $h_{\mathrm{t}} / \mathrm{t}_{\mathrm{f}}=0.18 ; \mathrm{t}_{\mathrm{f}}=1700 \mathrm{~nm} ;$ (b) $\mathrm{h}_{\mathrm{t}} / \mathrm{t}_{\mathrm{f}}=1.43 ; \mathrm{t}_{\mathrm{f}}=1700 \mathrm{~nm}$; and $(c) h_{\mathrm{f}} / \mathrm{t}_{\mathrm{f}}=9.96 ; \mathrm{t}_{\mathrm{f}}=240 \mathrm{~nm}$. 


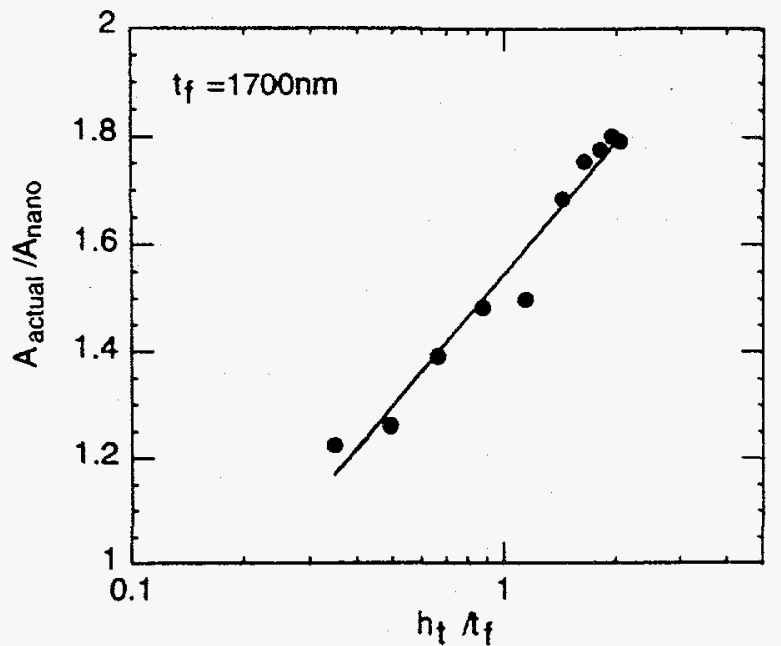

Fig. 3. Indentation depth dependence of $A_{\text {actual }} / A_{\text {nano }}$ for the $1700 \mathrm{~nm}$ film.

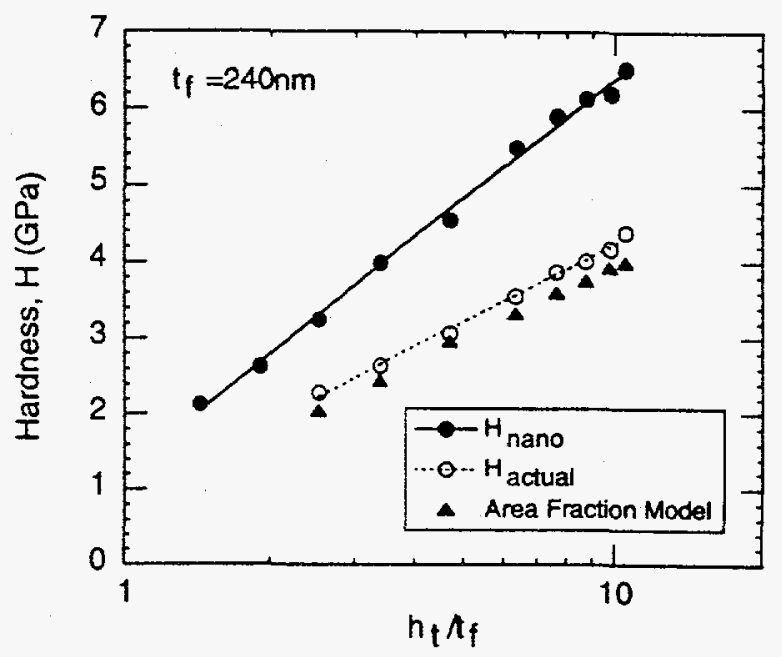

Fig. 4. Indentation depth dependence of the hardness of the $240 \mathrm{~nm}$ film.

substrate imposes on the plastic deformation in the film enhances pile-up by an amount which is greatest at indentation depths around the film thickness.

To further quantify this behavior, the actual areas of the indentations made in the $1700 \mathrm{~nm}$ film measured from SEM images are plotted as $A_{\text {actual }} / A_{\text {nano }} v s . h_{t} / t_{f}$ in Figure 3 . The results show that there is indeed an increase in contact area due to the pile-up and that the nanoindentation analysis procedures underestimate the true contact area by as much as $80 \%$. Clearly, this must be accounted for if accurate measurements of $\mathrm{E}$ and $\mathrm{H}$ are to be obtained; otherwise, errors as large as $80 \%$ in the hardness and $35 \%$ in the elastic modulus will result. For purposes of comparison, the hardnesses and elastic moduli computed from Eqns. 1 and 2 using the actual contact areas are plotted as the open circles in Fig. 1. It is seen that $\mathrm{H}_{\text {actual }}$ and $\mathrm{E}_{\mathrm{actual}}$ are reduced by a considerable amount, with the reduction being most important for penetration depths close to the film thickness. Furthermore, the measured elastic modulus does not increase in the region $h_{t}<t_{f}$, but is rather constant at a value close $70 \mathrm{GPa}$, the modulus of aluminum. Thus, it can be concluded that the experimentally observed increase in $E_{\text {nano }}$ with penetration depth is an artifact caused by not accounting for pileup in the measurement of contact area.

The decrease in elastic modulus at greater penetration depths has two separate origins. First, the modulus of the substrate, $57 \mathrm{GPa}$, is approximately $20 \%$ smaller than the film, so a small decrease is naturally expected. However, this by itself can explain neither the abruptness of the decrease nor the reduction in $\mathrm{E}_{\text {nano }}$ to values less than $57 \mathrm{GPa}$. Space considerations prohibit a complete explanation for this behavior, but in short, the lower than expected modulus is an artifact caused by the procedures used to estimate the unloading stiffness when the indenter penetrates through the film. During unloading, glass exhibits a much greater elastic recovery than aluminum. Thus, when the indenter penetrates the film into the glass, the displacements recovered during unloading are significantly different in the lower portion of the unloading curve, i.e., after contact with the aluminum is lost. This produces a bend in the curve and changes its shape in a way that the assumed power-law fitting relation does not fit well. The net effect is that unloading stiffness derived from the power-law fit is underestimated, which translates via Eqn. 2 to an underestimation of the elastic modulus. Indentations made in the 240 $\mathrm{nm}$ film were used to explore the film/substrate composite behavior when the indenter penetrates through the film. The composite elastic modulus was not considered due to the aforementioned problems in determining the contact stiffness.

Results of the composite hardness measurements are summarized in Fig. 4, which shows the depth dependence of the hardness computed in three ways. The filled circles are the hardnesses determined from standard nanoindentation procedures. These are in error not only because of the influences of pile-up on the contact area, but also because of the curve fitting 


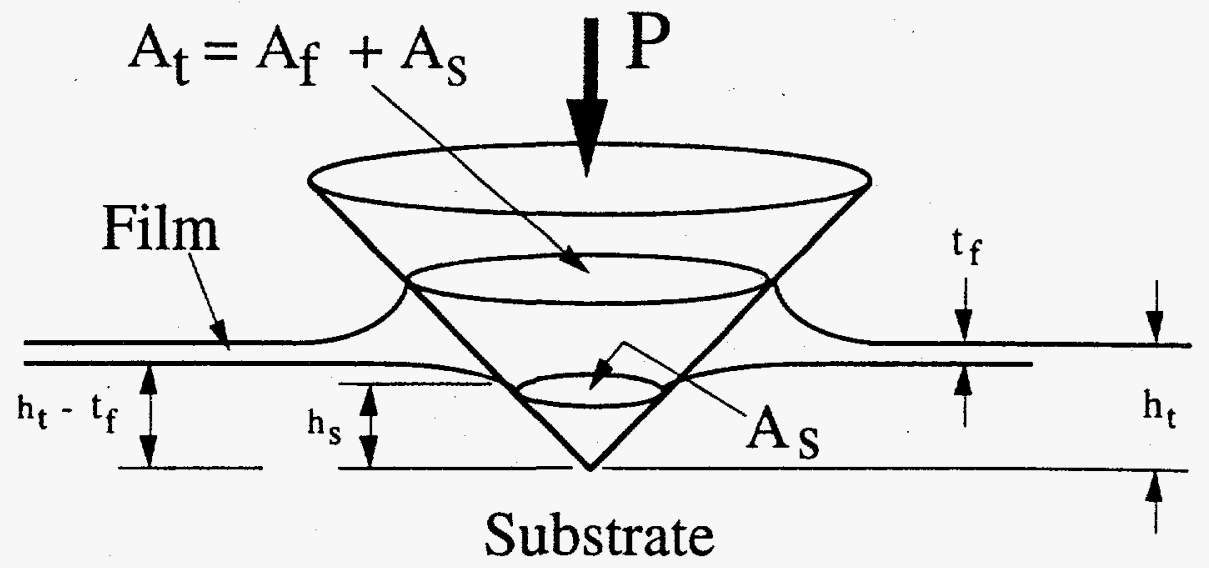

Fig. 5. Schematic illustration of the indentation of a soft film on hard substrate.

difficulties. The open circles are the hardnesses based on the actual area of contact. Comparing these two sets of data, it is clear that the curve fitting difficulties and failure to account for the pile-up result in the nanoindentation hardnesses being significantly greater than the actual hardnesses. The third set of data, shown as filled triangles on the plot, are the predictions of a simple model for the hardness of the composite film/substrate system. It is based on a rule of mixtures:

$$
H_{c}=\left(\frac{A_{f}}{A_{T}}\right) H_{f}+\left(\frac{A_{s}}{A_{T}}\right) H_{s},
$$

which states that the composite hardness, $\mathrm{H}_{\mathrm{c}}$, depends of the hardness of the film, $\mathrm{H}_{\mathrm{f}}$, and the hardness of the substrate, $\mathrm{H}_{s}$, through the relative fractions of the projected indentation area in the film, $A_{f}$, and the substrate, $A_{s}$. A diagram illustrating the important parameters is shown in Fig. 5.

To implement this rule of mixtures requires that all of the parameters on the right hand side of Eqn. 3 be independently measurable. For the sake of calculation, we assume here that $\mathrm{H}_{\mathrm{f}}$ is the hardness approached asymptotically at small depths and that $\mathrm{H}_{\mathrm{s}}$ is $7.0 \mathrm{GPa}$, i.e., the independently measured value for the substrate. The small depth hardness of the $240 \mathrm{~nm}$ film was $1.0 \mathrm{GPa}$, somewhat higher than the $1700 \mathrm{~nm}$ film. To determine the area fractions, we use the SEM measurements as the total area, $A_{t}$, and partition this area into film and substrate portions using an approximate procedure which could be useful when $A_{f}$ and $A_{S}$ cannot be measured directly. The basic assumption, as illustrated in Fig. 5, is that at a given indentation load, P, the interface between the film and substrate sinks in to produce the same deflection geometry that would occur if there were no film on the substrate. Such an assumption should hold reasonably well when $\mathrm{H}_{\mathrm{f}}<<\mathrm{H}_{\mathrm{s}}$ and/or $\mathrm{h}_{\mathrm{t}}>>\mathrm{t}_{\mathrm{f}}$. With this assumption, the depth along which contact is made between the indenter and the substrate, $h_{\mathrm{s}}$, can be computed from:

$$
h_{s}=\alpha\left(h_{t}-t_{f}\right),
$$

where the parameter $\alpha$ is the ratio of the contact depth to the total depth during indentation of the bare substrate. This parameter can be readily determined by standard nanoindentation measurements on the substrate. For the glass substrate used in this study, $\alpha=0.72$. Once $h_{s}$ is established, $A_{s}$ follows by evaluating the area function of the indenter at $h_{s}$, and $A_{f}$ can be computed from $A_{f}=A_{t}-A_{s}$.

Using these procedures, the composite hardnesses predicted by the model are plotted in Fig. 5, where it is seen that the predicted hardnesses are in generally good agreement with the actual hardnesses. The model could prove useful in measuring the hardness and modulus of soft films on hard substrates when it is not possible to make hardness impressions small enough to 
give substrate independent properties.

\section{ACKNOWLEDGMENTS}

This research was sponsored by the Division of Materials Sciences, U.S. Department of Energy, under contract DE-AC05-960R22464 with Lockheed Martin Energy Research Corp., and through the SHaRE Program under contract DE-AC05-76OR00033 between the U.S. Department of Energy and Oak Ridge Associated Universities. One of the authors (GMP) is grateful for sabbatical support provided by the Oak Ridge National Laboratory.

\section{REFERENCES}

1. W.C. Oliver and G.M. Pharr, J. Mater. Res. 7, 1564 (1992).

2. G.M. Pharr and W.C. Oliver, MRS Bull. XVII, 28 (1992).

3. P.J. Burnett and D.S. Rickerby, Thin Solid Film 148, 41-50 (1987).

4. P.J. Burnett and D.S. Rickerby, Thin Solid Films 148, 51-65 (1987).

5. M.F. Doerner and W.D. Nix, J. Mater. Res 1, 601-609 (1986).

6. M.F. Doerner, D.S. Gardner, and W.D. Nix, J. Mater. Res. 1, 845-851 (1987).

7. M.F. Doerner and W.D. Nix, CRC Critical Reviews in Solid State and Materials Science 14, 225-268 (1988).

8. B.D. Fabes and W.C. Oliver, Mat. Res. Soc. Symp. Proc. 188, 127-132 (1990).

9. W.R. LaFontaine, B. Yost, and C.-Y. Li, J. Mater. Res. 5, 776-783 (1990).

10. D. Stone, W.R. LaFontaine, P. Alexopoulos, T.W. Wu, and C.-Y. Li, J. Mater. Res 3, 141-147(1988).

11. D.S. Stone, Journal of Electronic Packing 112, $41-46$ (1990).

12. T.Y. Tsui, W.C. Oliver, and G.M. Pharr, J. Mater. Res. 11, (1996).

13. A. Bolshakov, W.C. Oliver, and G.M. Pharr, J. Mater. Res. 11, (1996).

\section{DISCLAIMER}

This report was prepared as an account of work sponsored by an agency of the United States Government. Neither the United States Government nor any agency thereof, nor any of their employees, makes any warranty, express or implied, or assumes any legal liability or responsibility for the accuracy, completeness, or usefulness of any information, apparatus, product, or process disclosed, or represents that its use would not infringe privately owned rights. Reference herein to any specific commercial product, process, or service by trade name, trademark, manufacturer, or otherwise does not necessarily constitute or imply its endorsement, recommendation, or favoring by the United States Government or any agency thereof. The views and opinions of authors expressed herein do not necessarily state or reflect those of the United States Government or any agency thereof. 